excellence set by Charles Lidz and his colleagues. In short the book is a masterpiece.

The authors set out to investigate how, in practice, informed consent worked in a psychiatric hospital. In particular they examined three clinical areas: a research ward, an out-patient clinic and an acute admission ward. The Mental Health Procedures Act, 1976 for the State of Pennsylvania had been enacted just prior to the study. Their theoretical framework rests on what they identify as the five components of the doctrine of informed consent. Certain information must be disclosed to a competent patient who should understand what he or she is told. From a position of complete voluntariness the patient should then make a decision which fully determines the outcome. How are these components to be measured? Clearly there is no psychiatric or psychological gadgetry that will do the job and too much interference by interviewers may distort the very procedure which is under scrutiny. The authors opted for two participant observers, one of whom 'lived with' the patients and the other with the staff. In this way the researchers breathed the air of the hospital and learned much of all those subtle, and sometimes not so subtle, ways in which information is communicated to and received by patients. A fascinating picture of life in the hospital emerges and any reader who finds it disturbing should sample something of the average British psychiatric hospital.

The many hours of eavesdropping, discussions and interviews are skilfully reported (much of them verbatim) and analysed. Some will be disturbed by the findings, others will not be surprised. The authors conclude 'that current informed consent policy has been a dismal failure', ... . it 'has not produced the results contemplated by its most ardent advocates'. But the discussion is more than a recital of familiar arguments; it has a freshness because it is free of psychiatric paternalism, legal nitpicking and arid philosophical theory. Indeed the authors suggest that their findings will cause little joy to both supporters and detractors of informed consent. The letter of the law was obeyed but in a ritualistic manner which frequently obscured its spirit. On the other hand patients were generally well looked after and there was no improper treatment because of failure to obtain informed consent. The study illustrates, above all else, what Professor Alan Stone describes in his foreword: namely, that the law is a blunt device with which to regulate the fine-tuning of complex human affairs.
From the introduction, which includes a critical review of previous empirical research, through the presentation of the study to the summary, the authors maintain a scholarly style which is free of polemics. The book is essential reading for all who have an interest in informed consent.

DEREK CHISWICK

Senior Lecturer in Forensic Psychiatry, Department of Psychiatry, University of Edinburgh

\section{Care of the Dying - A Clinical Handbook}

Nigel C H Stott and Flora G Finley, 83 pages, London, $£ 2.95$ (paperback), Churchill Livingstone, 1984

Science is objectivity and reason. Religion is subjectivity and intuition. Science follows the concept of rational morality - which is practical, analytical, rational and less emotional - but religious thinking is different - it is theoretical, empirical, moral and emotional. Both contradictory doctrines are practised by humans, not surprisingly, because contradiction is a characteristic feature of human nature. As far as the care of the dying is concerned, both schools of thought, mercifully, agree that one should 'begin at the beginning, go up to the end and then stop'.

This clinical handbook adopts a didactic approach, giving practical tips step by step as required in the care of the dying for a relative, friend, health worker and other helpers. Nineteen chapters deal with symptom control for pain, nausea, vomiting, constipation, intestinal obstruction, urinary incontinence, mouth care, anorexia, dyspepsia, hiccup, dyspnoea, cough, itch, pressure areas, fungating lesions, bleeding problems, compression syndromes, confusion, insomnia and weakness. The text is kept to a minimum and the book is illustrated by line drawings, making it an easy-to-read manual.

There are eight chapters devoted to the ethical aspects of care in keeping with care of the whole person: general approach, talking to patients and their families, avoiding confusion over therapy and food, the patient in the family, as death approaches, grief, religious differences and what to do after an expected death.

At the end there is a chapter on aids for the dying and some topics for discussion to give readers a chance to think things over and not feel they are being forced into a corner.

I congratulate the authors on the tactful presentation of the text which on the one hand gives advice according to rational morality and on the other encourages devoutly religious people to adhere to their religions and cultural beliefs. The freedom of choice which people value so much during their life is ensured at the time of dying.

Contradictory advice from philosophy and religion was in fact resulting in confusion and this book clarifies it in an excellent way. I recommend this book unreservedly to all health workers, relatives or friends who are likely to care for a dying person.

BASHIR QURESHI General Practitioner, 32 Legrace Avenue, Hounslow West Middlesex TW4 7RS

\section{Developments in Human Reproduction and Their Eugenic and Ethical Implications}

Editor, C O Carter, 236 pages, London, $£ 18.50$, Academic Press, 1983

As the preface to this book suggests 'men and women find technical advances affecting human reproduction disturbing'. This applies a fortiori to doctors who of necessity must deal with this minefield of research and clinical activity. The symposium on which this book is based, held in London in 1983, makes a significant contribution to this topical yet highly controversial field.

The first chapter by R J Aitken of Edinburgh deals with recent advances in contraception with special reference to a male pill Gossypol, pregnancy vaccination and derivatives of gonadotrophin releasing hormones. The literature is adequately covered but as ever one is depressed regarding the paucity of original thought and innovative flair in this field, a situation which has now lasted for several decades. Advances of a substantive nature have not been made; funding at the international level has been exiguous by any standards; the lead times prior to clinical investigation enforced by regulatory bodies such as the Food and Drug Administration (FDA) in North America have cast long and inhibitory shadows. Prospects for the future cannot be viewed with much optimism and at the time of writing there seems little likelihood of any major breakthrough until the mid-21st century at the earliest. 